Images dans le monde ibérique et ibéricoaméricain

$8 \mid 2015$

L'Histoire et ses récits entre images, fictions et paratextes

\title{
Informar, instruir y controlar: Las notas de Fray Pedro de San Cecilio (1596-1668) sobre la fundación de la recolección mercedaria
}

\section{Manuela Águeda García Garrido}

\author{
(2) OpenEdition \\ Journals \\ Edición electrónica \\ URL: http://journals.openedition.org/agedor/489 \\ DOI: 10.4000/agedor.489 \\ ISSN: 2104-3353 \\ Editor \\ Laboratoire LISAA
}

Referencia electrónica

Manuela Águeda García Garrido, «Informar, instruir y controlar: Las notas de Fray Pedro de San Cecilio (1596-1668) sobre la fundación de la recolección mercedaria », L'Âge d'or [En línea], 8 | 2015, Publicado el 01 febrero 2016, consultado el 22 abril 2019. URL : http://journals.openedition.org/ agedor/489; DOI : 10.4000/agedor.489 


\title{
Informar, instruir y controlar: Las notas de Fray Pedro de San Cecilio (1596-1668) sobre la fundación de la recolección mercedaria
}

\begin{abstract}
Résumé: Cet article vise à analyser la signification qu'acquièrent, dans le contexte socioculturel et religieux du XVII ${ }^{e}$ siècle, les notes marginales introduites par le frère mercédaire Pedro de San Cecilio, aux documents qu'il avait réunis concernant la récollection de son ordre. Aussi, avancerons-nous quelques pistes permettant d'expliquer dans quelle mesure la volonté historiciste du chroniqueur fut conçue en tant que stratégie d'ascension au sein de sa province. Celle-ci était alors soumise à un processus constant de restructuration interne dont les religieux les plus avantagés apprirent à tirer profit en vue d'accéder aux charges les plus convoitées et les plus honorables.
\end{abstract}

Mots clés: Chroniques - manuscrits - mercédaires - récollection - Andalousie - XVIIe siècle

Resumen: Este artículo pretende analizar el significado que adquieren, en el contexto sociocultural y religioso del siglo XVII, las notas marginales aportadas por el fraile mercedario Pedro de San Cecilio a los papeles que reunió sobre la fundación de la recolección de su orden. Ofreceremos asimismo algunas pistas que permitan explicar en qué medida la voluntad historicista del cronista fue concebida como una estrategia de ascensión en el seno de su provincia mercedaria, sumida entonces en un continuo proceso de reestructuración del que los religiosos más aventajados supieron sacar provecho para optar a codiciados y honorables cargos.

Palabras clave: Crónicas - manuscrito - mercedarios - recolección - Andalucía - Siglo XVII

Y quando virtudes del cielo buscan tierna magestad para su abrigo, muy sagrado feudo es que estos blasones honrosos con que Dios ha coronado a sus pobres euangélicos confiesen a los pies de V. Magestad que, como a la del cielo deuen sus laureles, a la de la tierra deuen sus aclamaciones'.

$\mathrm{P}$ ara llevar a cabo una reforma religiosa eficaz, entre otras estrategias institucionales, la Iglesia tejió su propia red de información poniendo a su servicio un amplio y obsecuente personal eclesiástico (comendadores, comisarios, fiscales, jueces y notarios apostólicos, oficiales, priores, provinciales, secretarios, visitadores...), con funciones administrativas concretas. Todos ellos estaban encargados de generar la documentación que exigía la férrea autoridad episcopal para controlar a todos los fieles adscritos a su jurisdicción.

El granadino Fray Pedro de San Cecilio, eminente cronista de los descalzos de la Orden de la Merced, fue uno de los muchos religiosos andaluces que pusieron sus talentos al servicio de su congregación, favoreciendo con ello el progreso de la reforma mercedaria que vio la luz el 8 de

\footnotetext{
${ }^{1}$ Dedicatoria de fray Juan de Santa María al rey Carlos II. Citado por fray Pedro de San Cecilio en Annales de la Orden
} de Descalzos de Nuestra Sra. de la Merced, tomo II, 1669, s.f. 
mayo de 1603, seis años después de que apareciera la nueva edición de las constituciones, redactadas por el general de la orden Fray Francisco Zúmel (1593-1599). El padre San Cecilio, que poseía una sólida formación en teología, adquirida en el convento de San José de Sevilla y en el de Osuna, además de unas excelentes dotes narrativas, no tardó en desempeñar importantes funciones dentro de su orden, como las de comendador del convento de Fuentes (1624-1626) y las de definidor de la provincia de Andalucía. La información que nos ha llegado hasta hoy de su producción intelectual (N. Antonio, J. A. Garí y Siumell, G. Placer López y J. Sánchez Blanco) demuestra que el amanuense mercedario había consagrado buena parte de su vida a reunir bulas, concesiones, motus proprii, breves, correspondencia eclesiástica y muchos otros textos manuscritos, para redactar sus Annales del orden de descalzos de nuestra señora de la merced redempción de captivos (Barcelona, Dionisio Hidalgo, 1669). El resultado se convirtió de inmediato en una útil herramienta para informar a sus superiores del estado y avance de la reforma, enseñar a sus nuevos hermanos de hábito los logros de la orden y demostrarles con ello cuáles eran las direcciones que la reforma debía tomar.

Sin embargo, el arsenal documental del que dispuso el fraile mercedario para emprender tamaña tarea se reunió en numerosos volúmenes manuscritos, de los cuales tres se conservan hoy en el fondo antiguo de la biblioteca universitaria de Sevilla ${ }^{2}$. Su inmensa erudición se hace visible tanto en las precisas notas biográficas, topográficas y cronológicas, como en las generosas referencias a las autoridades escriturarias y patrísticas. De la misma manera, el profundo conocimiento de la historia, la estructura, el funcionamiento y las prácticas litúrgicas de su orden se manifiesta en las glosas que se extienden profusamente en los márgenes del centenar de folios que constituye el volumen de Papeles varios, en particular la pieza 16: La relación de la fundación y cosas particulares de la recolección, escrita de su puño y letra por Fray Luis de Jesús María.

Este artículo pretende analizar, en una primera parte, el significado que adquieren, en el contexto sociocultural y religioso de la época, las notas marginales aportadas por Fray Pedro de San Cecilio en los papeles que reunió sobre la fundación de la recolección, con la clara intención de redactar las primeras crónicas de la orden tras la adopción de la reforma. Explicaremos así si deben clasificarse como comentarios valorativos, anecdóticos, explicativos, sancionadores, enmendadores o estrictamente sapienciales. En última instancia, ofreceremos algunas pistas que permitan explicar en qué medida la voluntad historicista del fraile mercedario, acentuada en sus abundantes glosas, acotaciones y apostillas, fue concebida como una estrategia de ascensión en el seno de su provincia mercedaria, sumida entonces en un continuo proceso de reestructuración del que los religiosos más aventajados supieron sacar provecho para obtener honorables cargos. La infatigable tarea de cronista debió de ser rentable para el padre San Cecilio, en la medida en que le permitió obtener un cargo superior que atrajo ingresos nada desdeñables a su provincia y convento.

\section{La documentación manuscrita de fray Pedro de San Cecilio en la crónica de la reforma mercedaria}

Redactar la crónica de una orden religiosa en la España moderna suponía un arduo trabajo de composición que aspiraba a «referir en todo y por todo cómo se deue la verdad de lo

\footnotetext{
2 El presente artículo se centrará en el Ms A 330/139. Este manuscrito lleva el título de Papeles varios escritos o reunidos por el Padre Fray Pedro de San Cecilio de la Orden de la Merced, relativos a los Conventos de dicha Orden y a las vidas de algunos religiosos que vivieron con ellos (s.d.), 389 fols. Se encuentra en el fondo antiguo de la Biblioteca universitaria de Sevilla. En adelante, B.U.S.
} 
sucedido» ${ }^{3}$, siguiendo por lo general un modelo historiográfico de inspiración patrística. En este sentido, prima una clara tendencia agustiniana. Inmortalizar con la pluma el carácter y la misión de aquellos hombres y mujeres que consagraron su vida a la Iglesia significaba atestar la grandeza de la obra de Dios en la tierra, o lo que es igual, contribuir al mantenimiento del espíritu de exaltación contrarreformista en una época fuertemente marcada por los enfrentamientos confesionales entre los que urgía la necesidad de validar un discurso de renovación católica ${ }^{4}$. El cronista se consideraba el elegido para asumir una misión providencial y de orden profético. Su gesta narrativa se enmarcaba así en un amplio proyecto teleológico de la historia eclesiástica al que se adherían, en particular, los religiosos de las órdenes mendicantes. Fray Diego Murillo, religioso franciscano de la provincia de Aragón, lo expresaba con esclarecida convicción: «suele tener la prouidencia de Dios algunas personas señaladas, a quien comunica espíritus tan feruorosos, que se estienden a más de lo que la obligación precisa de su estado requiere» ${ }^{5}$. Esta misma providencia sometía al cronista al servicio de un poder teocrático que recompensaba su fidelidad con el codiciado premio de la salvación y la posesión de un cargo privilegiado en el seno de la congregación. Los ejemplos son innumerables. Fray Andrés de San Nicolás, cronista de los agustinos recoletos (Madrid, 1664), fue habilitado para todos los cargos de su orden excepto para el del generalato ${ }^{6}$. Andrés de Guadalupe fue promovido al cargo de vicario de la provincia de los Ángeles en 1651 y tras la aparición de su Historia (Madrid, 1662) lanzó su carrera eclesiástica, siendo nombrado vice-comisario de la familia cismontana y comisario general de Indias ${ }^{7}$. Fray Tomás Velázquez, eminente cronista franciscano de la provincia de los alcantarinos, fue nombrado repetidas veces ministro y definidor general de su orden ${ }^{8}$.

Buena parte de esas obras panegíricas de las órdenes religiosas que configuraron el mapa religioso de la monarquía hispánica tras el concilio de Trento fueron impresas a lo largo de la edad moderna, naciendo así un fenómeno que, según los historiadores, vino a inaugurar una etapa de claro «despliegue publicístico» o incluso una «explosión historiográfica” » sin precedentes. No obstante, el volumen que representan estas obras impresas queda aún por estimar, no existiendo al día de hoy estudios de síntesis que hagan referencia a la totalidad de las crónicas impresas de las órdenes religiosas presentes en el territorio peninsular y, aun menos, estudios sobre su aporte al conocimiento de la historia religiosa de la España moderna ${ }^{10}$.

Las lagunas que han quedado sin colmatar en la historiografía española, en relación con las fuentes cronísticas de las diversas familias religiosas, se extienden ampliamente cuando nos referimos a las obras manuscritas, al estar aún sin catalogar de forma sistemática y lejos del ámbito de interés de los historiadores modernistas. Esta documentación manuscrita, a pesar de su considerable aporte informativo, no ha conseguido ocupar un lugar central en la historia religiosa.

\footnotetext{
${ }^{3}$ RAMÓN, Alonso, Historia general de la orden de nostra señora de la merced, vol. 2, proemio al lector de fray Francisco de Benavides, Madrid, imprenta del reino, 1639, s.f.

${ }^{4}$ Se trata de un discurso de exaltación del mensaje evangélico al servicio de la Reforma católica que aparece de forma recurrente en la mayoría de los sermones. Este discurso se apoyaba en la celebración de la dedicación de Jerusalén para evocar de forma alegórica la renovación de toda la Iglesia católica: Facta sunt autem encenia in Hyerosolimis et hiemps erat, Iohannes 10, 22.

${ }^{5}$ CARRILLO, Juan, Primera parte de la Historia de la tercera orden de nuestro Seráphico padre san Francisco, Zaragoza, Lucas Sánchez, 1610.

${ }^{6}$ FABO, Fray Pedro, Historia de la provincia de la Candelaria de agustinos recoletos, vol. II, Madrid, 1914, p. 75-102.

${ }^{7}$ LUENGO, Fray Juan, Vida del reverendíssimo y venerable padre Fray Andrés de Guadalupe, Madrid, Juan García Infanzón, 1680, libro IV, cap. I, p. 338.

${ }^{8}$ Escribió la Vida del V. Fray Francisco Molinero, Granada, Antonio de Torrubia, 1698. Cf. Biografía eclesiástica completa, vol. 29, Madrid, Alejandro Gómez Fuentenegro, 1868, p. 1174. José Simón Díaz atribuye esta obra a Fray Tomás de Montalvo. Cf. Bibliografía de la literatura hispánica, vol. XV, Madrid, C.S.I.C., 1992, p. 216.

${ }^{9} \mathrm{El}$ trabajo de reunión y catalogación de la documentación es colosal. ATIENZA LÓPEZ, Ángela, Iglesia memorable, Madrid, Sílex, 2012, pp. 25 y 27. DOMÍNGUEZ ORTIZ, Antonio, habla de «tarea inabordable», en Las clases privilegiadas en el Antiguo Régimen, Madrid, Istmo, 1985, p. 202-203.

${ }^{10}$ Sigue siendo una referencia el Indicador de crónicas religiosas en España, de Juan Pío GARCÍA PÉREZ, Madrid, viuda de Manuel Tello, 1901.
} 
Una de las principales razones estriba en que las crónicas manuscritas no sólo se definen por seguir una línea discursiva plagada de desaforados elogios y una clara finalidad encomiástica sino que, a diferencia de lo que ocurre con la cronística impresa, tienen menor alcance. Por lo tanto, la llamada «guerra de órdenes» que propicia este género narrativo redujo considerablemente su campo de acción que, en muchos casos, coincidía con el espacio jurisdiccional de un convento, lugar en el que se dirimían los conflictos internos de la congregación y se establecían las bases inamovibles de la jerarquía eclesiástica ${ }^{11}$. Dicho de otro modo, las crónicas manuscritas contribuyeron igualmente a engrosar la ingente documentación hispánica dedicada a dar cuenta de la epopeya misional de la Iglesia contrarreformista. Sin embargo, de alguna manera, quedaban relegadas a una función auxiliar, vinculada a la literatura devocional o de edificación personal. Se definían como una obligada referencia bibliográfica para los predicadores de cada familia religiosa. Asimismo, quedaron restringidas a un uso local (el del convento y la provincia) y tuvieron una agitada existencia, pues muchas de estas crónicas fueron destruidas o se perdieron durante los procesos de desamortización que tuvieron lugar en el siglo XIX.

La obra manuscrita de fray Pedro de San Cecilio tiene la particularidad de haber sobrevivido a las azarosas vicisitudes del tiempo desde que en 1630, según indica el mismo religioso en sus notas, se dedicara a ensamblar los documentos (testimonios orales, bulas, motus proprii, breves, decretos, correspondencias, informes de beatificación...) que daban fe del progreso de la recolección mercedaria ${ }^{12}$. Para entonces, hacía ya casi veinte años que el religioso granadino profesaba en el convento San Laureano de Sevilla ${ }^{13}$, provincia de la Concepción. Hay que señalar que ya se conocían en el seno de la orden algunas muestras del género cronístico en forma manuscrita. Fray Marcos de Ostos había redactado Fragmentos misceláneos de las cosas memorables de esta provincia de Andalucía [...] durante el tiempo en que fue provincial de la misma, entre 1622 y $1625^{14}$. Fray Francisco de la Cruz escribió una Crónica de la orden de nuestra señora de la Merced que permanecería inédita en el archivo del convento madrileño de Santa Bárbara ${ }^{15}$. También fue un granadino, fray Andrés de San Agustín, quien legara una ingente producción cronística que jamás llegó a la imprenta.

$\mathrm{Al}$ igual que los primeros cronistas de la reforma mercedaria (Fray Bernardo de Vargas o fray Alonso Remón), Pedro de San Cecilio tenía por vocación plasmar por escrito las proezas de la orden en un tiempo de profunda renovación religiosa. El hecho de que muchas de estas crónicas hayan quedado fuera del circuito trazado por el libro impreso no nos autoriza, en cambio, a afirmar que el manuscrito seguía teniendo prioridad en las prácticas de lectura de la España del siglo XVII. Debemos incidir más bien en que las historias manuscritas relativas a la orden mercedaria y, por lo general, a todas las familias religiosas, se conciben como sólidos soportes de justificación doctrinal, badenes de la nueva espiritualidad que irrigaba la catolicidad postridentina e incluso, como manuales de devoción que se dirigen a un lector dispuesto a iniciar

\footnotetext{
${ }^{11}$ El dominico Antonio de Lorea (1635-1687) no llegó a imprimir su Historia de la provincia de Andalucía, entre otras razones, por no haber superado los conflictos personales que había acumulado con el maestro de su orden, Tomás de Rocabertí (1670-77) a quien le desagradó la audacia de que se nombrara a sí mismo «cronista de la orden». Cf. SÁNCHEZ-HERMOSILLA, Francisco (O.P.), «Biografía de fray Antonio de Lorea Amescua, o.p.», Communio: revista semestral publicada por los Dominicos de la provincia de Andalucia, (36), Sevilla, Studium General, 2003, p. 209-237.

${ }^{12}$ La relación fue solicitada personalmente por el provincial de la Concepción, Hernando de Santa María : «Que esta relación retroescrita la hizo a mi instancia y mandato el padre fray Luys de Jesús María que oy es prouincial de Castilla, estando en esta prouincia del Andalucía y está escrita de su mano y lo firmé por ser verdad en este conuento de Sanlúcar oy lunes doze de septiembre de mil y seyscientos y veintidós». Ms. Papeles varios, fol. 173v.

13 Tomó el hábito el 19 de febrero de 1611 y profesó el 15 de julio del año siguiente, es decir, doce años después de la fundación del colegio sevillano. El provincial de Andalucía era entonces el maestro Melchor Guerrero. Véase JORDÁN FERNÁNDEZ, Jorge Alberto, «Algunas noticias de los primeros años de vida del convento de la merced descalza de Osuna, sacadas de los papeles del P. Pedro de San Cecilio», Apuntes 2, (5), Ayuntamiento de Osuna, 2007, p. 153.

${ }^{14}$ Se trata del manuscrito 3.600 conservado en la Biblioteca Nacional de España. En adelante B.N.E.

15 GARÍ Y SIUMELL, José Antonio (O. de M.), Biblioteca Mercedaria, Barcelona, Imprenta de los herederos de la viuda de Pla, 1875, p. 84.
} 
la fragosa andadura de la recolección ${ }^{16}$. Los tímidos inicios del fenómeno reformador, así como la exclusividad que suponía participar en el mismo, teniendo en cuenta la discreción que imponía el deseo de inaugurar un modelo pionero de vida religiosa, sólo podía manifestarse con un claro desprecio por la divulgación de la cultura impresa ${ }^{17}$.

No obstante, el trabajo de fray Pedro de San Cecilio gozaría del privilegio de llegar a la imprenta de Barcelona en 1669, con el título de Annales del Orden de Descalcos de N.S. de la Merced. Consta la obra de dos voluminosos tomos que abarcan el periodo comprendido entre 1603 y 1660: la historia completa de la recolección mercedaria que el cronista había incluido previamente en tres volúmenes manuscritos y esmeradamente encuadernados. La disposición de la obra impresa y el cambio de estilo narrativo que se observa en el segundo tomo permiten distinguir dos plumas diferentes. Fray José del Espíritu Santo, que había sido provincial, definidor general, comendador de Madrid y predicador de Felipe IV, fue quien dio principio a la impresión de los Annales por consejo del vicario general Fray Juan de Santa María. Hemos de tener presente que el padre San Cecilio había fenecido el 19 de enero de 1668 sin haber redactado totalmente el segundo tomo ${ }^{18}$.

\section{De la información a la instrucción religiosa en las notas manuscritas de fray Pedro de San Cecilio}

En la aprobación que otorgó el padre Ramón de San Jerónimo para la impresión del primer tomo de los Annales, se insistía en el admirable esfuerzo que había realizado su autor "para tapar la boca a la emulación más satírica», haciendo así referencia a la producción cronística de otras familias religiosas que habían iniciado el itinerario de la descalcez a un mismo tiempo ${ }^{19}$. Suponía un gran desafío para fray Pedro de San Cecilio el relatar el periplo de la reforma mercedaria sin caer en los tópicos historiales empleados por otros cronistas. Contaba para ello con los testimonios manuscritos de sus correligionarios difuntos a los que presentaba como hombres imbuidos por la providencia (varones santos) ${ }^{20}$ para exonerarlos de toda responsabilidad en la posible tergiversación histórica. No en vano, fray Luis de las Infantas, sabiendo que fray Pedro de los Ángeles, provincial andaluz de la Concepción desde el 17 de mayo de 1642, tenía intenciones de confiar a un cronista la memoria de la recolección, en una carta que le remitió a su superior, expuso lo que fue una preocupación constante en los inicios de la congregación: «[...] le suplico por amor de nuestro procurador que no ponga lides ni pendencias como los demás Choronistas,

\footnotetext{
${ }^{16} \mathrm{La}$ tendencia a redactar escolios puede interpretarse como una técnica de apropiación de las obras devocionales surgidas de las tensiones y rivalidades que se habían instaurado entre las congregaciones religiosas. MONER, Michel et alii, Paratextos en la literatura española, siglos XV-XVIII. Madrid, Casa de Velázquez, 2009, p. XVI.

${ }^{17}$ La reforma de la recolección, como ocurrió en otros ámbitos, se ve impulsada por nuevas prácticas de lecturas entre las que el texto manuscrito ocupará un lugar privilegiado. En este sentido, Fernando Bouza infiere que, entre los doctos, se observa un claro interés por cualquier forma manuscrita de marginalia, rellenar cartapacios de citas o elaborar sumas del contenido de los libros leídos. Cf. Comunicación, conocimiento y memoria en la España de los siglos XVIy XVII, Salamanca, SEMYR, 2000, p. 84-85.

${ }^{18}$ GARÍ Y SIUMELL, José Antonio, Biblioteca..., op. cit., p. 71.

${ }^{19} \mathrm{El}$ caso de los agustinos es más que emblemático, pues en el primer cuarto del siglo XVII, ya habían fundado 13 conventos, situación sólo parangonable a la de los trinitarios. Para una visión de conjunto, véase MARTÍNEZ CUESTA, Ángel, «El movimiento recoleto en los siglos XVI y XVII», Recollectio, O.A.R., 1982, p. 5-47. También Historia de los Agustinos recoletos, Madrid, editorial Augustinus, vol. 1, 1995; GARCÍA ORO, José (O.F.M.), «Los frailes descalzos. La nueva reforma del Barroco», Archivo ibero-americano, 60, (237), 2000, Madrid, , pp. 511-587; MARTÍNEZ MILLÁN, José, «El movimiento descalzo en las órdenes religiosas», La monarquía de Felipe III, Madrid, Mapfre, vol. 1, 2008, p. 93-111.

${ }^{20}$ Annales, 1a parte, p. 15, 115, 166, 168, 177, 249, 463 y 503
} 
el Maestro Vargas y el maestro Remón» ${ }^{21}$. En una carta remitida por el padre San Cecilio al padre provincial de Andalucía fray Juan Guerrero, que estaba preparando una relación del convento de la merced de Sevilla, el religioso previene de las «mil nieblas ocasionadas del ignominioso descuido de los que nos precedieron» y advierte a sus superiores que no deben reiterarse las incorrecciones cometidas por fray Pedro de Cíjar ${ }^{22}$. Evitar conflictos y pleitos de legitimidad con otras órdenes para permitir el avance de la recolección era uno de los principales objetivos de aquellos religiosos ${ }^{23}$.

El mismo fray Luis de Jesús María, comendador del convento de San Laureano de Sevilla y uno de los cuatro fundadores de la reforma, refirió dilatadamente los tropiezos de los primeros tiempos. En sus parcas notas manuscritas, no dudó en mencionar algunos de esos incidentes que fray Pedro de san Cecilio no incluye en sus Annales: «Bien así es verdad que a auido desde entonces acá infortunios en la religión y que a auido quien la persiga así hijos adulterinos de ella como otros de fuera» ${ }^{24}$. Se refería aquí el padre Jesús María a los diferentes episodios que frenaron el progreso de la reforma. Hay que tener en cuenta que todos estos estaban relacionados con conflictos jurisdiccionales de los frailes contra la autoridad señorial o episcopal existente en los lugares de fundación. Uno de ellos, que se transformó en un pleito de más de ocho años, fue el que protagonizó el marqués Rodrigo Enríquez de Mendoza, segundo esposo de la fundadora del convento de Valdonquillo (León), Francisca Osorio, por la primavera de 1616. Otro sonado conflicto fue el que mantuvieron los frailes en la villa de Argamasilla de Alba (Toledo) en 1612 por apropiarse de la ermita de santa Ana. En 1608, los mercedarios tuvieron que enfrentarse en Fuentes (Badajoz), a la negativa de oficiar misa, según ordenó el obispo Juan de la Sal ${ }^{25}$. Asimismo, en el adviento de 1609, en la villa de Lora (Sevilla), los frailes mercedarios tuvieron que ignorar los desmanes de los franciscanos por apropiarse del mismo espacio fundacional. Estos datos fueron recogidos en los Annales del cronista mercedario, en muchos casos escrupulosamente enmendados, con la intención de cumplir dos objetivos fundamentales: informar e instruir a la comunidad de recoletos mercedarios, acercándolos así a la realidad histórica de la descalcez.

El objetivo de informar aflora en la mayoría de las notas que añadió el padre San Cecilio a la Relación de la fundación que se inserta en el volumen anteriormente mencionado de Papeles varios. Las 25 acotaciones diseminadas en los 16 folios numerados $\left(155 \mathrm{r}^{\circ}-173 \mathrm{v}^{\circ}\right)$ de la dicha pieza muestran en qué medida el carácter informativo adquiere un protagonismo mayor, haciendo de los márgenes un espacio mnemotécnico donde el cronista se encargaba de citar ideas, hechos y fechas memorables. Se trataba de elementos aislados que luego servirían de indicadores para acceder al contenido que había de sustentar la redacción de sus Annales. Tras su atenta lectura, podemos establecer varias categorías tipológicas que nos permitan analizar en toda su complejidad las razones y particularidades de la práctica de la anotación al margen.

Hay notas escriturarias, que se refieren a pasajes de las Sagradas Escrituras (Sal. 51, 118; Ct. 2,4; Os. 2; I Co. 1, 26) o a tratados de los padres de la Iglesia, tanto latinos como griegos (San Atanasio, san Agustín, san Juan Clímaco...).

\footnotetext{
${ }^{21}$ Carta de fray Luis de las Infantas a fray Pedro de los Ángeles, Úbeda, 14 de octubre de 1642, Ms 567 Fragmentos de Andalucía, fol. $471 \mathrm{r}^{\circ}$.

${ }^{22}$ Esta relación, que ha permanecido inédita, se conserva en la B.N.E. (Ms 2441). Véase la transcripción completa de la carta en anexo.

${ }^{23}$ El cronista mercedario Felipe Colombo heredaría la misma responsabilidad de su predecesor cuando en 1684 tuvo que imprimir una réplica (Crisol del desengaño, Madrid, Antonio González), a las calumnias que el dominico Antonio de Lorea había publicado sobre la orden de la merced.

24 Ms. Papeles varios, fol. $159 \mathrm{v}^{\circ}$.

${ }^{25} \mathrm{El}$ contencioso que mantuvieron en 1614 los mercedarios descalzos con el cardenal Gaspar de Borja, arzobispo de Sevilla, pone de relieve la capacidad de movilización de contactos (Roma, la Corte, el valido, la casa ducal de Medina Sidonia...) que podía poseer una orden religiosa para llevar a cabo sus objetivos fundacionales. Véase ATIENZA LÓPEZ, Ángela, Tiempos de conventos: una historia social de las fundaciones en la España moderna, Madrid, Marcial Pons, 2008, p. 352-353.
} 
Las notas cronológicas son abundantes. Algunas aluden a la muerte de un religioso. La del general Alonso de Monroy, el 10 de agosto de 1645 (fol. 159vº) o la de fray Luis de Jesús María el 8 de mayo de 1625, «como el año que se descalcó» (fol. $163 \mathrm{v}^{\circ}$ ), son datos que subrayan la singularidad del personaje que se ensalza. Otras apuntan a recalcar el año de redacción de un hecho concreto: «Esto se escribió el año de 1619 o el siguiente de 1620, estando el padre Fr. Luys de Jesús María en el convento del Visso» ${ }^{26}$.

Tampoco faltan las notas ratificatorias que recuerdan al cronista la obligación que tenía de corroborar la veracidad de los hechos: «Tenía nuestro padre Fr. Juan Bautista, quando se fundó la recolección, cincuenta años de edad y treinta y uno de hábito, pero el obispo de Rosse defiende (y con buenas razones) que no tenía más que cincuenta años de edad, y es lo cierto» ${ }^{27}$. En dos ocasiones, incide en que fray Luis de Jesús María «es el que escribió de su mano esta relación ${ }^{28}$, quizás con una doble intención: atribuir una incuestionable veracidad a la fuente escrita y, por la autoridad que confería la señalada pluma de uno de los cuatro primeros fundadores de la recolección, evitar toda posible disensión generada por los acontecimientos relatados.

Las notas correctoras sirven para enmendar datos precisos de la fundación, a los cuales se añaden fechas que sitúan el momento en que aquellas se escribieron. En 1632, el fraile escribe al margen derecho del folio $160 \mathrm{r}^{\circ}$ que: «El convento de Milán no se fundó quando dize esta relación». Y estaba en lo cierto, pues habría que esperar hasta diciembre de 1635 para ver fundado el convento de la ciudad italiana, a instancias de fray Andrés de la Concepción, comendador de Palermo, y con la donación de Don García Bravo de Acuña, castellano de Milán. La nota que se añade en la parte inferior del margen, induce a pensar que el cronista revisó al menos dos veces sus documentos manuscritos y que a cada lectura de sus fuentes introdujo acotaciones nuevas de gran valor informativo: «Aunque sea fundado el convento de Milán y se escribe esto el año de $1640{ }^{29}$.

La voluntad de instruir a aquellos hermanos de orden que habían demostrado claros «deseos de perfeccionarse», se manifiesta en algunas de las notas que añadió el cronista a la relación manuscrita de la fundación, completando así una suerte de mapa espiritual de la reforma. Los comentarios marginales del padre San Cecilio testimonian la necesidad que tenía la orden de rememorar el extraordinario entusiasmo de aquellos veinte años que siguieron a la fundación de la descalcez mercedaria. Sus numerosos comentarios manuscritos se inscriben en una táctica de revalorización del espíritu de cohesión, disciplina y militancia dentro de la reforma ${ }^{30}$. Dicho de otro modo, los comentarios del cronista ponían de relieve las claves de la vida monástica que luego servirían para tejer un relato con el que los miembros del instituto pudieran guiar y controlar el futuro de la recolección. No obstante, aquella exaltación de la vía espiritual palidece ligeramente en los Annales $^{31}$. Nuestro cronista tenía la obligación de noticiar la herencia de la recolección mercedaria. Ésta reposaba en dos aspectos esenciales que debían seguir en vigor en el seno de la orden: la perfección de la caridad por medio de la oración y el recogimiento, así como la aspereza y estrechez de la regla (pobreza, abstinencia, humildad, penitencia, clausura...). La

\footnotetext{
${ }^{26}$ Fol. $160 r^{\circ}$.

${ }^{27}$ Fol. $160 v^{\circ}$.

${ }^{28}$ Fols. $162 \mathrm{v}^{\circ}$ y $163 \mathrm{v}^{\circ}$

${ }^{29}$ Las notas correctoras son numerosas en otras piezas del volumen de Papeles varios. En la pieza 5, informando de todos los comendadores del convento de la Almorayma, nota en el margen derecho: «Todo esto no fue así y yo, quando lo dixe, estaba mal informado. Después, he tenido mejor relación porque e visto los libros antiguos del conuento de la Almorayma y por él consta que el padre Fr. Juan Bautista tuuo la encomienda desta casa hasta setiembre dicho 4 y la renunció. Y por su renunciación eligieron los superiores por comendador al padre Juan Miguel de las Llagas, que tuuo el oficio desde fin de setiembre dicho 4, hasta el capítulo de Cazorla celebrado el año de 1607», fol. $96 \mathrm{r}^{\circ}$.

30 ATIENZA LÓPEZ, Ángela, Tiempos de conventos..., op. cit., p. 41.

${ }^{31}$ Sobre la visión del ascetismo original de la orden, remitimos a GARCÍA BERNAL, José Jaime, Iglesia memorable..., op. cit., p. 219.
} 
nota del folio $167 \mathrm{v}^{\circ}$ sobre el ejercicio de la vida espiritual tras la fundación del convento del Viso (Córdoba) refleja la preocupación del cronista por ofrecer más tarde, en su crónica, una suerte de guía de espiritualidad de la recolección para la educación de los novicios. Recordemos que éste era el séptimo y último capítulo del decálogo de las constituciones del instituto, «la zanja y fundamento desta Reformación $\rangle^{32}$. La reforma había nacido como un renuevo en el olivo de la congregación y era indispensable controlar su rápido crecimiento. Las numerosas notas marginales sobre este punto demuestran que aquello representaba algo más que una simple metáfora de la fundación. Por lo tanto, para el cronista, describir a los novicios como ramas que florecen en el seno de la Iglesia, no sólo suponía volver al origen providencial de la orden que tuvo lugar en la revelación de san Pedro Nolasco, sino reavivar el espíritu de renovación constante en los futuros vástagos de la congregación. La nueva milicia cristiana de la orden redentora de cautivos disponía así de sólidas herramientas para desplegar su actividad pastoral en un amplio marco de control institucional. La cita salmódica extraída de la Vulgata que aparece en el margen derecho del folio $159 \mathrm{r}^{\circ}$ se enmarca así en el fundamento espiritual de la orden: Ego autem sicut olina fructifera in domo dei, sperani in misericordia Dei in aternum et in seculum seculi (Ps. 51, $10)^{33}$. La glosa escapaba a la tenuidad, pues eran los salmos, así como ciertos pasajes del Cantar de los Cantares, textos referenciales en la misa cantada que la liturgia mercedaria imponía en sus conventos. En este sentido, las notas del padre San Cecilio sobre las prácticas litúrgicas de la recolección son rutilantes aciertos de su misión cronística que resurgirán ampliamente en los Annales con la idea de enseñar a sus hermanos cuáles eran las autoridades que daban fuste al cariz ascético de la descalcez ${ }^{34}$.

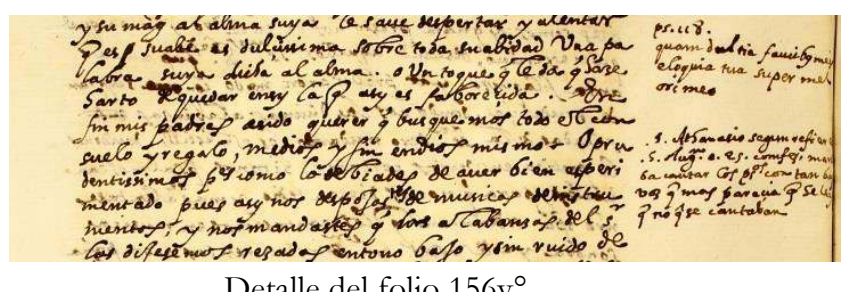

Detalle del folio $156 v^{\circ}$

\section{Finalidad de la labor cronística: recursos para medrar}

Más allá de ver en las notas del padre San Cecilio la extensión de un espacio de autoridad ${ }^{35}$ o el medio que da cabida y justifica la sublimación literaria del cronista, hemos de tener en cuenta otros elementos meta-textuales que, en cierta medida, capacitan el sentido último del texto, sin despreciar el valor simbólico del mismo. Entre ellos, es fundamental conocer la intención del cronista, para quien los recursos técnicos no serían más que un subterfugio que permitiera llevar a cabo una misión prioritaria en el seno de su orden: informar e instruir a sus hermanos y controlar la dirección que iba tomando el fenómeno de la reforma.

\footnotetext{
32 Annales, primera parte, p. 298.

${ }^{33}$ En la Biblia de Reina-Valera (1960): Sal. 52, 8.

${ }^{34}$ Los primeros descalzos ya habían dado a la estampa tratados de perfección que conocía fray Pedro de San Cecilio. Citamos a continuación sólo algunos de los más notorios: Fray Alonso de Rojas, autor de Día espiritual y de contemplación [...], Cuenca, Gaspar Selma, 1604. Fray Jorge de San Francisco, comendador del Viso y de Osuna, autor de Vuelo del espiritu y escala de perfección, Granada, 1612. Fray Juan Núñez Franco, de la provincia de la Concepción, escribió Ejercicios espirituales, Sevilla, s.l., 1623. A Fray Pedro de la Serna, sevillano de nacimiento, se le atribuye un Cielo espiritual, trino y uno, Sevilla, 1633.

35 Françoise CRÉMOUX habla de «puissance prescriptive» que domina e incluso termina reemplazando al texto. Véase su artículo, «Marge prescriptive, marge destructrice ? Réflexions sur quelques manuscrits et imprimés $\left(\mathrm{XV}^{\mathrm{e}}\right.$ XVII" siècles)», Pandora, (9), Université Paris VIII, 2009, p. 28.
} 
La legitimación de la recolección partiendo de una exposición laudatoria de los méritos santificadores de sus miembros es una de las claras finalidades de nuestro mercedario. Prueba de ello es la protestación que redactó en los prolegómenos de los Annales acomodándose a los últimos decretos del papa Urbano VIII sobre las prácticas canónicas en relación con el culto de santos. El del 5 de julio de 1634, que ratificaba uno anterior de 1625, modificaba el proceso de canonización y beatificación. En cuanto a la constitución de 1642, establecida por la sagrada congregación de ritos de Roma, prohibía que se publicaran hagiografías sin la aprobación de los ordinarios. El padre San Cecilio aclara con su protestación que los elogios hacia sus hermanos de orden no dimanan de la Iglesia de Roma sino de su propia autoridad humana y de la opinión de santidad que aquellos hombres gozaban entre los suyos. Su autoridad como cronista es acreditada, de algún modo, por sus superiores jerárquicos, lo que convierte a la orden reformada en una identidad plenipotenciaria a mediados ya de la década de 1640.

La obtención del reconocimiento a su labor es igualmente un objetivo claro en su función cronística. Las anotaciones que aparecen en los márgenes de lo que luego será el soporte de su memorial de la descalcez revelan su preocupación por trazar y fijar en la memoria de todos el brillante cursus honorum de los protagonistas de la recolección. Procuradores, provinciales, definidores, secretarios, vicarios, comendadores y demás cargos de gobierno de la orden se prestan a todo tipo de comentarios marginales que terminan formando parte de un corpus que el padre San Cecilio utiliza para configurar una genealogía del mérito. Su propio itinerario personal, aunque ausente en sus notas, reclama un lugar honorable en la Historia de la orden. Sin embargo, ¿obtuvo realmente ese lugar nuestro religioso?

Su estancia en diferentes conventos andaluces le permitió estrechar relaciones amistosas, intelectuales y espirituales con insignes varones de su familia religiosa. Sabemos que permaneció buena parte de su vida en el convento de San José de Sevilla aunque pasaría por los de Fuentes, Granada, Huelva y Sanlúcar ${ }^{36}$. Allí compartiría los rigores de la descalcez con otros venerables religiosos. Destacaban entre ellos: fray Cristóbal de san Pedro Nolasco, electo $23^{\circ}$ comendador de Rota en el capítulo de Sanlúcar celebrado el 28 de abril de 1657; fray Juan de San Gabriel, $19^{\circ}$ comendador de Rota y Ayamonte o el maestro de novicios fray Juan de San Ramón, alias de Miravalles. Falleció el 19 de enero de 1668 en el convento de Rota donde debió de conocer al que fuera luego su sucesor en la orden: fray Andrés de San Agustín ${ }^{37}$. Sus hermanos lo consideraban

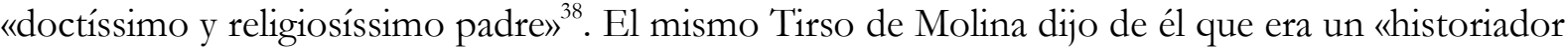
digno de aprecio» ${ }^{39}$, una opinión que aprovecharon otros religiosos de la orden para continuar o enmendar sus trabajos inéditos. Fue el caso de fray Antonio del Espíritu Santo, lector de teología en la provincia de Castilla ${ }^{40}$ o de fray Juan de la Presentación, teólogo y nuevo cronista de la $\operatorname{orden}^{41}$. Nuestro religioso recibió todo tipo de elogios a lo largo de su carrera eclesiástica. De hecho, la congregación supo recompensar la labor de nuestro incansable religioso, como lo prueba la carta que fray Melchor Rodríguez de Torres, obispo de Rosse (Irlanda), remitió a fray Juan de San Ramón, vicario general de la orden, con fecha del 23 de septiembre de 1639. En aquella carta, le suplicaba lo siguiente:

\footnotetext{
36 Electo comendador del convento de Fuentes, en el capítulo de Huelva de 1624. Detentó la encomienda del convento hasta octubre de 1626 «en que fue absuelto por el padre fray Joan de San Ramón, que era prouincial». Ms 330/119, fol. 140vº.

37 Provincial de Castilla en 1646 y rector del convento de Rota en 1675, el nuevo cronista encarnaría a la perfección la figura del mercedario recompensado por su congregación, siguiendo así el camino ya balizado por su predecesor.

38 SAN AGUSTÍN, Fray Andrés de, Dios prodigioso [...], Sevilla, Tomás López de Haro, 1688, p. 118.

39 «Tirso de Molina: ensayos sobre la biografía y la obra del maestro fray Gabriel Téllez», Revista Estudios, Madrid, Revista publicada por los frailes de la Orden de la Merced, 1949, p. 37.

${ }^{40}$ Autor de Dios prodigioso en Teresa de Jesús, Madrid, Dionisio Hidalgo, 1669.

${ }^{41}$ Imprimió una hagiografía ampliada ya escrita por San Cecilio en 1629: El machabeo evangélico. Vida del glorioso doctor san Pedro Pascual de Valencia, Madrid, imprenta real, 1671.
} 
Haga toda merced al padre de San Cecilio, pues tal zelo del hábito, tal deseo de su honra y tal afecto a sus cosas, en 77 años que ha conozco la orden, no he hallado en ella persona que en las prendas referidas le haga ventaja, ni aun le iguale. Esto me ha causado tal amor con él, que ha años no me correspondo con otros, porque le hallo con indicios de predestinado ${ }^{42}$.

Los favores que recibió el padre San Cecilio a lo largo de su carrera también favorecieron a su provincia de Andalucía ya que sus escritos aumentaron la devoción y la caridad de generosos protectores de la orden, como fueron la Condesa de Tarifa, la de Osuna, doña Teresa Pimentel, duquesa de Sessa, la casa de Medina Sidonia o el obispo Blas de Tineo, entre otros ${ }^{43}$. Apenas diez años después de recibir el hábito en San Laureano, nuestro fraile gozaba ya de una respetable reputación como estudioso de las antigüedades ${ }^{44}$. En este sentido, se decía gran conocedor de la obra ciceroniana y coincidía con el gran orador latino en la concepción de la Historia como patrimonio. Narrar el nombre y hechos gloriosos de los padres inducía sin duda a perpetuar la memoria en los hijos. El trabajo de elaboración de una crónica garantizaba la existencia de una memoria institucional a partir de la cual se pudiera definir un proyecto de identidad comunitaria. No obstante, su incansable tarea de cronista demuestra que la eternidad no es sólo privilegio de hombres memorables. Sabiéndose hacedor de eternidades, las palabras de Cicerón se identifican plenamente con las suyas: «Mi fortuna actual es suficiente para atender a mis necesidades; a mis hijos con el nombre paterno y la memoria de los servicios que he prestado a la república, les dejo rico patrimonio» ${ }^{45}$.

\section{Conclusiones}

El conjunto de los marginalia que salen de la mano del padre San Cecilio presentan una extensión variable. Hay notas muy breves: «Fundación del Visso» (fol. 167r $\mathrm{r}^{\circ}$ ); «El domingo dexamos la visión» (fol.169r $\mathrm{r}^{\circ}$ ); «en visión imaginaria» (fol. 170v ${ }^{\circ}$ ). Y frente a estas, hay otras también bastante densas, que son las que corresponden principalmente al primer tipo de notas anteriormente expuesto: las escriturarias. Todas ellas pretenden ampliar y completar el sentido que exponen los pasajes elegidos de los padres de la Iglesia con la firme intención de recordar, fijar y transmitir el carisma espiritual de la orden.

Sin embargo, aunque se muestran sumamente relevantes, las notas marginales no llegan a reemplazar nunca al texto, por lo que no es posible adjudicarles en este caso el valor de

\footnotetext{
${ }^{42}$ Carta reproducida por DE LA PRESENTACIÓN, Juan, El machabeo evangélico..., op. cit., p. 153-154.

43 Doña Isabel de Sandoval, duquesa de Osuna, apoyó la litigiosa demanda de traslado de los mercedarios de Osuna residentes en Santa Ana, desde 1637, Archivo de la Colegiata de Osuna, Actas Capitulares, tomo III, 1625-1641, fol. $44 \mathrm{v}^{\circ}$ et sqq. Doña Juana de Mendoza, duquesa de Béjar, solicitó que en las oraciones y sermones de los mercedarios se pidiera por su familia y por el alma de los fundadores, AHN, Nobleza, Osuna, C 3519, D. 21 y 389 , D. 5. Más allá de la nobleza, la devoción fue grande. El capitán Francisco de Villalba incluyó una cláusula en su testamento para entregar al convento de los mercedarios de Rota los 5 ducados de rédito anuales que generaba un censo de 100 ducados de vellón impuesto sobre sus propiedades. Archivo Histórico Nacional, Clero, libro 2078, Protocolo del convento de la Merced de Rota, fol. 169r ${ }^{\circ}$.

44 En una carta que remitió al padre provincial Fray Juan Guerrero, le instaba a que no imprimiera nada sin su supervisión: «Avíseme V.P. el estado en que tiene sus trabajos y cómo le va de Historia de la provincia. Suplícole se sirva de no imprimirla sin que io la vea, porque entiendo (y el diablo sea sordo) que en cosas de la Religión, tengo tan buena noticia como el que más, si no más que todos, por los muchos años que e tratado esto e inmensidad de libros y papeles que e leído [...] pues no solamente me correspondo con los mejores historiadores de España, pero con algunos de Italia y Flandes; y a unos y otros solicito para que en sus libros hagan honrosas menciones de nuestra religión», Carta del 10 de noviembre de 1643, Ms 567 Fragmentos de Andalucía, fol. 480v.

45 De domo sua, «liberis autem nostris satis amplum patrimonium paterni nominis ac nostrae memoriae relinquemus» [Obras completas de M. T. CICERÓN. Trad. de Díaz Tendero, Madrid, tomo V, Librería de Perlado, 1919, p. 145].
} 
«metatexto» ${ }^{46}$. Lo que sí se aprecia es una relación claramente analítica entre el texto y las glosas, fenómeno que impuso entonces una nueva modalidad de lectura más allá del ámbito de la literatura devocional, pues ya sabemos que existe un amplio desarrollo del aparato paratextual para la literatura de ficción española del siglo XVII ${ }^{47}$.

La ausencia de escolios explícitos ha dejado también huella del trabajo realizado por nuestro mercedario. Adjunto al pasaje en el que se narra la pesadumbre que sintieron los religiosos por las querellas que levantó en mayo de 1603 el Doctor Valencia, cura de la villa de Mejorada, se lee en el margen derecho «Nota». Con toda probabilidad, el padre San Cecilio quiso disponer aquí de algunos apuntes sobre el desafortunado episodio fundacional en el que estaban involucrados nada más ni nada menos que el cardenal arzobispo de Toledo que, en la ocasión, era don Bernardo de Rojas y Sandoval ${ }^{48}$. Si bien es cierto que el padre Jesús María imprimió a estos sucesos expurgatorios de los primeros años de la descalcez un marcado tinte providencial, el cronista general se mostraba mucho más atento a la mediación humana que frenó o impelió la reforma. Así es como, en aquellas notas previas a los Annales, nuestro fraile pone ya a prueba su destreza historicista.

Esta misma capacidad del cronista mercedario a construir la historia institucional de su orden fue la que le permitió ocupar un lugar insigne entre aquellos hombres que imprimieron un sello indeleble a la reforma de la descalcez mercedaria. Su interés por recuperar los detalles que daban pleno sentido al designio providencial de la comunidad reformada no sólo modificó y enriqueció los márgenes de la documentación manuscrita que el fraile consiguió reunir en aras de la memoria eclesiástica de su congregación. Fray Pedro de San Cecilio utilizó las notas como herramienta historiográfica para hacer hincapié en el modo en que cada religioso sufría las tribulaciones inherentes a la recolección. Aquellas notas que, en ocasiones, podían resultar farragosas, sustentaron el relato de los itinerarios individuales que recibieron amplia recompensa por su sacrificio y entrega a la obra de Dios entre los hombres. Esa misma misión acercaba la vida del cronista a la de sus hermanos. Sin embargo, para el fraile mercedario no se trataba sólo de alcanzar el premio celeste, aquellos «blasones honrosos» que ya mencionaba en la dedicatoria de sus Annales, sino de medrar en el seno de la Iglesia católica, en un contexto histórico en el que la ascensión social era posible no sólo por acumulación de méritos sino por el respeto y la estima de aquellos que llevaban ventaja ${ }^{49}$.

\footnotetext{
${ }^{46}$ Françoise CRÉMOUX, « Marge prescriptive... », p. 26.

${ }^{47} \mathrm{La}$ obra de referencia es de CAYUELA, Anne, Le paratexte au Siècle d'Or. Prose romanesque, livres et lecteurs en Espagne au XVII siècle, Genève, Droz, 1996.

${ }^{48}$ Fol. $164 v^{\circ}$. Tres rúbricas casi idénticas, con la misma finalidad recordativa, aparecen también en el folio $170 v^{\circ}$ para remarcar la singular toma de hábito de la beata Catalina de la Cruz.

49 «Seruir mucho y medrar poco en el mundo se acostumbra, donde la sinrazón premia por el antojo, no por el mérito», DE LIZANA, Francisco (O. de M.), Primera escuela de Dios en la primera fábrica de sus obras, Madrid, Pablo de Val, 1653, tomo I, p. 238.
} 


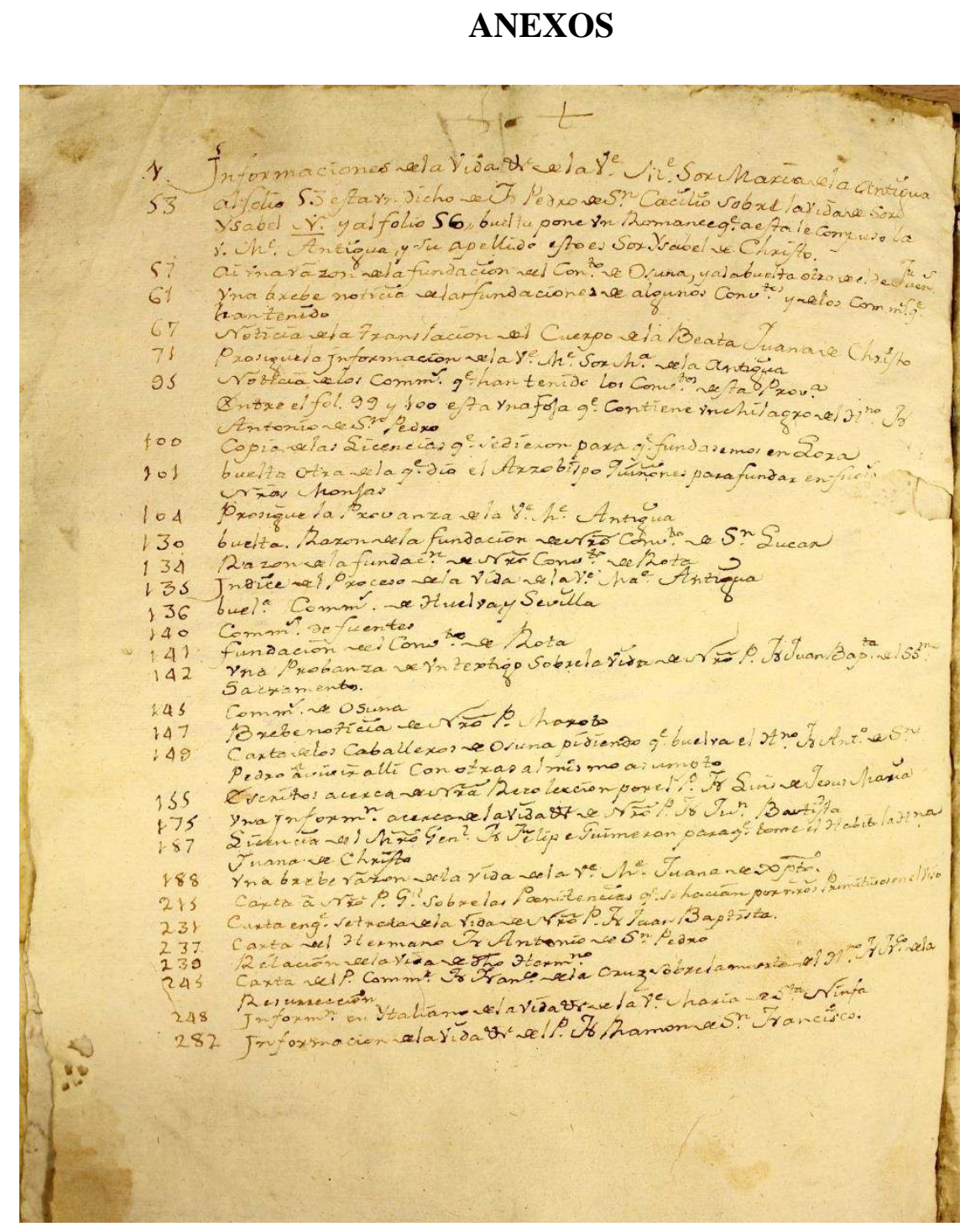

1. Índice del volumen Papeles varios, del cronista Pedro de San Cecilio. Ms A 330/139. Copia de la B.U.S. 


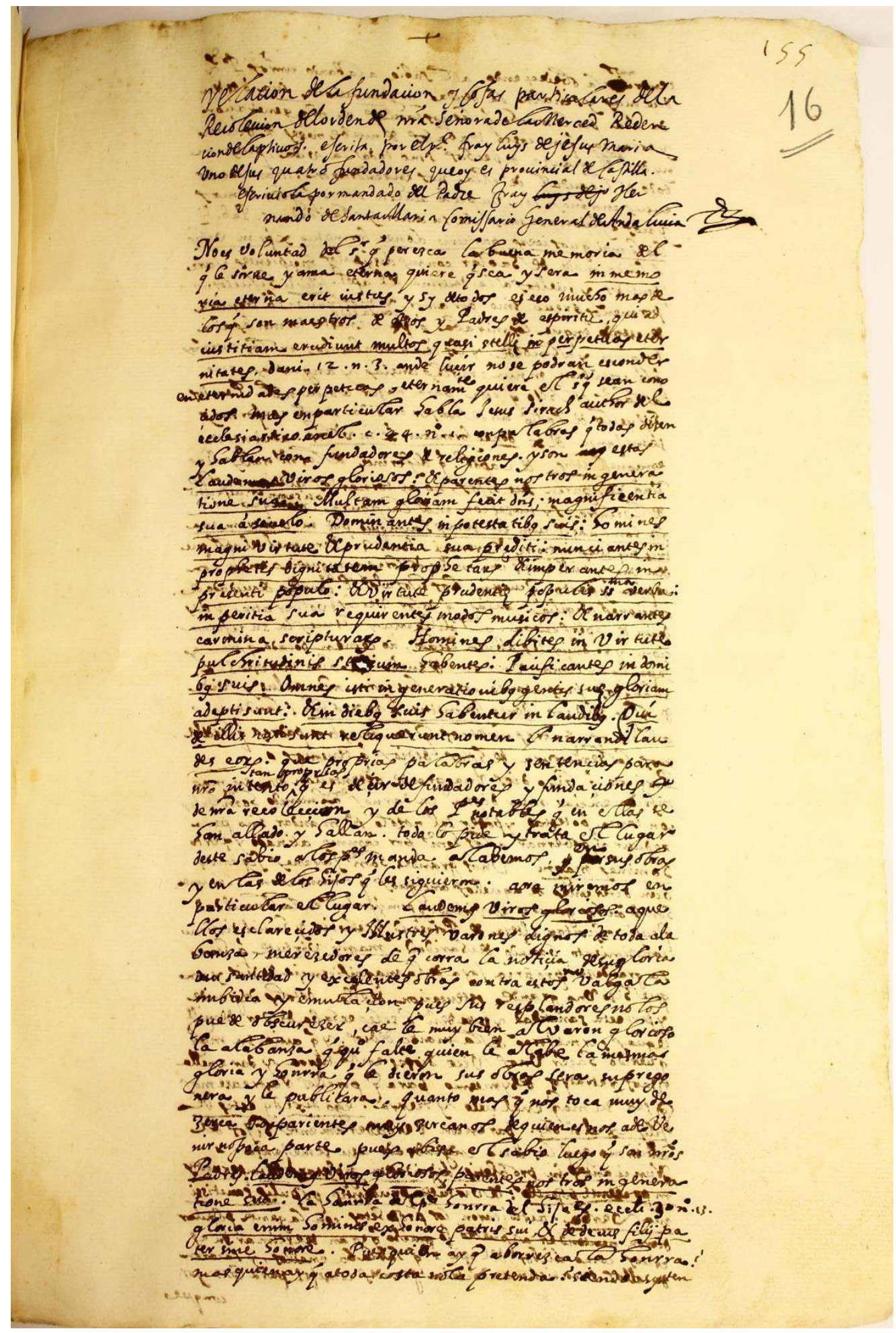

2. Primer folio $\left(155 r^{\circ}\right)$ de la relación sobre la recolección mercedaria. Ms A 330/139. Copia de la B.U.S. 
3. Carta del padre Fray Pedro de San Cecilio, mercedario descalzo, fols. $473 \mathrm{r}^{\circ}-475 v^{\circ}$. Extraída del ms. 567: Fragmentos de Andalucía. Madrid, Biblioteca de la curia provincial de la merced de Castilla.

De nuestro Señor a mi muy santo padre maestro fray Juan Guerrero, la salud y vida que deseo y muy santas y alegres Pasquas etc.

Bien estoy con todo lo que el padre dice pero en ninguna manera consiento que me cargue la culpa de mal correspondiente y ponga duda en el deseo que tengo y siempre tube de escribirle. Quanto a lo primero digo que suelo recibir algunas cartas tan añejas (ya sabrá vuestro Padre la causa, y si no, investíguela y dará luego con ella) que ia me parece sería dar los buenos años por maio querer responder a ella. Y suelo decir, pues se han pasado diez estafetas sin culpa mía, poco hace al caso pasen otras dos con ella. No todo le puede decir y los que somos mujeres honradas, avemos de disimular y paliar las faltas de nuestros maridos. En lo del deseo de servirle, digo mucho diciendo nada, que soy enemigo de repetir principios. Vengo, pues, al caso y digo assí:

Que con esta, remito a vuestro Padre el papel del convento que por la suya me pide, y con él, una muy curiosa relación de los conventos y provincias de Indias, que no dexará de hacerle al caso para muchas cosas. Va también un traslado de las cláusulas que el maestro fray Pedro de Cíjar escribió en su libro tantum quinque, tocantes a los mártires de nuestra religión, si bien lo que dice de fray Joan de Granada y fray Pedro de Malasanc yerra manifiestamente por las razones que el tesorero Pedraza pone en el capítulo en que trata de estos dos santos.

Acompaña estos papeles la relación del martirio de fray Alonso Gómez de Encinas, por si vuestro Padre no ha visto el libro de donde se sacó. Y con todo ello, van ciertas cláusulas sacadas del Palentino, de cosas tocantes a nuestra religión, por si le diera gana de pelear con el padre Calancha, que alega a este autor contra nosotros, como si no dixese más en nuestro abono que en nuestra contra.

Mucho me alegro tenga vuestro Padre su obra en tan buen punto como me dice y que lo aya aplaudido tanto por nuestro padre reverendísimo. No esperaua yo menos de cosas dispuestas por el ingenio de vuestro Padre ni lo que le dixe en la pasada fue con ánimo de querer yo enmendar lo que vuestro padre con tanto acuerdo hace, pues sus borrones tienen maior primor que mis líneas. El intento fue ver si acerca de lo que vuestro padre dice, me acuerdo de algunas de las muchas cosas que tengo vistas e investigadas para avisarle de ellas, y que a su modo las ordene si le pareciere emparangonarlas con las demás. En orden a esto, admito el fauor que promete hacerme de que io lo vea todo antes que se imprima. Estimo también la merced que dice vuestro Padre me hizo en hablarle de mí a su reverendísimo. Lo cierto es que le deseo ver porque es pariente mío muy cercano, no menos que primo segundo y por si viene por aquí, tengo a punto de imprimir la vida de nuestros santos mártires, fray Pedro de Malasanc y fray Joan de Granada, con fin de dedicársela. Entiendo no le pesará ver lo mucho que en el libro se descubre de cosas de la religión, o ignoradas de todos, o sabidas de muy pocos. Y de esos, con mil nieblas ocasionadas del ignominioso descuido de los que nos precedieron. Será el libro de cosa de veinte pliegos y lo bueno que tiene es que no anda vagabundo por esas tierras de Dios. En la orden entra y en ella persevera hasta la última letra del Laus Deo.

La segunda parte de Vargas, no sé quién la tenga. En otra librería, ay una que le faltan algunos pliegos y he deseado hallarla, no puedo descubrirla. Andaré con cuidado y si la hallare, serviré a vuestro Padre con ella.

Suplícole no se descuide de remitirme a Calancha, que me hace grandísima falta. Y si ese padre que le tiene quiere satisfación, daré la que vuestro Padre le ofreciere. Aí está el padre comendador de ese convento. Si vuestro Padre es servido de darle el libro para que le traiga, recibiré en ello singular merced.

En lo del dotor Espino, ay largo silencio. Díxose la semana pasada y oy le a reforzado la nueba que le hacían fiscal del consejo de Inquisición para lo de las monjas de san Plácido; no sé qué verdad tenga. Todavía le acuden los dominicos con tanta publicidad que les sirven en la 
audiencia de procuradores, a despecho del Arzobispo, que es el que le persigue. Quid de hominem futurum sit, tempus manifestabit.

Deseo saber de qué lugar fue natural el general pasado Dalmacio y no faltará en ese convento quien lo sepa, en este ninguno ay. Hágame vuestro Padre merced de preguntarlo y avisarme de ello.

No es cosa nueba para mí que las obras de nuestro Padre maestro Sabedra tengan la erudición digna de tal sujeto, antes lo sería que alguna de ellas dexase de ser numeris omnibus absoluta, porque como conozco su mucha profundidad y doctrina desde que recibí el hábito en san Laureano, el año de 1611 y vi entonces su mucho lucimiento, aun de sus descuidos hago grande concepto, quanto más de lo que le a costado tantos años de cuidado y desvelo. No sé si tiene su paternidad la aprouación que dio a sus proposiciones el Padre Pedro de Jesús María. Si no la tiene, se la remitiré, que en mi poder la tengo. Vuestro Padre le bese en mi nombre la mano y le diga que si ubiere de poner en su libro la aprouación del Padre fray Pedro de Jesús, haga dél algún elogio digno de su pluma, que todo lo mereció aquel gran varón, de quien Dios nos privó porque no lo merecíamos. Y todo se lo deve al mucho amor que le tubo y alto concepto que de sus cosas hizo.

Días a que tengo noticia de la promoción del Señor Arzobispo, Don Zebrián, pues llegó la nueba a Granada, diez días después que se le hizo la merced y luego me lo avisó el Señor Obispo Tineo. Alegréme de ella, pero no me admiré, porque espero cosas mucho mayores antes de muchos años y si vuestro Padre vibe lo que le deseo, hallará que todos estos son rudimentos. Lo que io quisiera es ver muy empeñados en favorecer la religión los que salen della con tanta honra. Pero de quantos havemos conocido no sabemos cosa de momento y más vale lo que uno solo dellos ha sacado de la orden, que lo que todos juntos han echo por ella. Por ventura a llegado Zebrián a tan alto puesto porque siempre se mostró mui hijo de su hábito. Plegue a Dios haga aora alguna honrada demostración de su buen zelo.

No quiero cansar más a vuestro Padre. Nuestro Señor me le guarde como deseo, con los aumentos que merece.

En Granada, diciembre 8 de 1643.

De vuestro Padre mui hijo, fray Pedro de san Cecilio. 